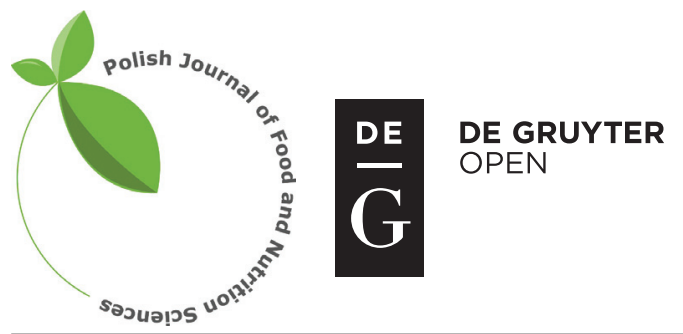

Pol. J. Food Nutr. Sci., 2017, Vol. 67, No. 3, pp. 233-240

DOI: $10.1515 /$ pjfns-2017-0004 http://journal.pan.olsztyn.pl

Original research article

Section: Food Technology

\title{
Effect of Green Tea Extract-Enriched Diets on Insulin and Leptin Levels, Oxidative Stress Parameters and Antioxidant Enzymes Activities in Obese Mice
}

\author{
Hana Bártíková, Iva Boušová, Petra Matoušková, Barbora Szotáková, Lenka Skálová* \\ Department of Biochemical Sciences, Faculty of Pharmacy, Charles University, \\ Heyrovského 1203, CZ-500 05, Hradec Králové, Czech Republic
}

Key words: monosodium glutamate-induced obesity, catechins, oxidative stress, polyphenon 60

Green tea and green tea extracts (GTE) are often incorporated into diet intended to weight reduction, although the information about their efficacy in obese individuals is insufficient. The present study was designed to follow up the effect of defined and standardized GTE in mice with obesity induced by monosodium L-glutamate. Obese mice were fed with GTE-supplemented diet in three dosage regimens: 28-day and 3-day intake of $1 \mathrm{~g}$ GTE in $1 \mathrm{~kg}$ of diet and 28-day intake of $0.1 \mathrm{~g}$ GTE in $1 \mathrm{~kg}$ of diet. The information on body weight, food intake, oxidation stress parameters in blood and antioxidant enzymes activity in liver and small intestine was obtained. High doses of GTE decreased the specific activities of glutathione reductase and catalase and increased concentrations of malondialdehyde in blood. Specific activities of antioxidant enzymes in the liver and small intestine were not altered after GTE treatment except the decrease of NAD(P)H:quinone oxidoreductase activity. Our results showed that GTE did not affect average body weight and did not markedly improve antioxidant status in glutamate-induced obese mice. Moreover, intake of high doses of GTE made antioxidant defense in obese animals even worse.

\section{INTRODUCTION}

Obesity, which is becoming one of the most severe health threats, is characterized by excessive fat accumulation in adipose tissue and other organs. This disease is often accompanied with conditions such as type 2 diabetes, dyslipidemia, insulin resistance, leptin resistance, and hepatic steatosis [Osei-Hyiaman et al., 2008]. Besides, cellular oxidative stress is increased in obese adipose tissue due to chronic local inflammation [Picklo et al., 2012]. Studies on the pathogenesis and/or therapy of this complex metabolic disorder depend on the appropriate animal models. Monosodium glutamate (MSG)-induced obesity, which belongs to the often used animal models of obesity, has been also reported as a suitable model for realization of nutritional intervention studies [Alarcon-Aguilar et al., 2007; Fujimoto et al., 2012a,b] .

Repeated subcutaneous MSG administration to rodent neonates results in a loss of neurons in the hypothalamic arcuate nucleus leading to the impairment in the insulin and leptin signaling with subsequent hyperleptinemia and hyperinsulinemia and also to the changes in energy balance as well as pituitary and adrenal activity [Olney, 1969; Matyskova et al., 2008]. In contrast to the most of genetic models (e.g. $o b / o b$ or $d b / d b$ mice), MSG-induced obesity develops without hyperphagia and there is no need of high-fat diet administra-

\footnotetext{
* Corresponding Author: Tel.: +420495067322; Fax: +420495512665;

E-mail: lenka.skalova@faf.cuni.cz (Lenka Skálová, Ph.D.)
}

tion, which may compromise results of the nutritional intervention studies. Our previous study showed significant differences in the activity and/or expression of various antioxidant enzymes in the liver and small intestine of MSG-induced obese mice in comparison with lean counterparts [Matouskova et al., 2015].

There are many natural products affecting energy balance and leading to body weight reduction [Afrin et al., 2016; Akaberi \& Hosseinzadeh, 2016; Amiot et al., 2016]. Green tea and/or green tea extract, prepared from leaves of Camellia sinensis (Theaceae) represent one of the most popular 'natural' products for weight management. Green tea polyphenols, especially flavan-3-ols also known as catechins, are considered to be responsible for the health benefits of green tea, including prevention of cancer and cardiovascular diseases, the anti-inflammatory, antiarthritic, antiviral, neuroprotective, and cholesterol-lowering effects [Chacko et al., 2010; Johnson et al., 2012].

As the supplements usually contain concentrated phytochemicals, consumed doses highly exceed those that could be obtained from food. Therefore, apart from anticipated health improvement, it is necessary to keep in mind possible unexpected effects, especially interactions between tea constituents and various enzymes. Tea catechins may directly affect enzymatic activity and/or modulate enzyme expression via various signaling pathways [Khan et al., 2006; Na \& Surh, 2008; Martin et al., 2010]. As antioxidant enzymes keep redox balance and protect organism against reactive 
oxygen species (ROS), their modulation by tea catechins might have important consequences. Several studies, including our previous study, have shown that green tea polyphenols are able to modulate the expression and/or activity of antioxidant enzymes, such as glutathione peroxidase (GPx), superoxide dismutase (SOD), catalase (CAT), glutathione reductase $(\mathrm{GR}), \mathrm{NAD}(\mathrm{P}) \mathrm{H}$ :quinone oxidoreductase (NQO) and glutathione S-transferase (GST) in healthy lean mice or rats [Khan et al., 1992; Na \& Surh, 2008; Wiegand et al., 2009; Bartikova et al., 2015]. However, there are only limited information about the effect of green tea on antioxidant status of obese animals.

For this reason, the present in vivo study was designed to follow up the effect of green tea extract (GTE) on the activity of several antioxidant enzymes in the liver and small intestine of mice with MSG-induced obesity and metabolic syndrome. Concurrently, food intake, body weight and oxidative stress parameters in plasma and/or erythrocytes were measured. Polyphenon 60, the defined and commercially available form of GTE, was used in three different regimens: 28-day and 3-day intake of $0.1 \%$ GTE (simulation of long-standing and short-standing overdose consumption of GTE in dietary supplements) and 28 -day intake of $0.01 \%$ of GTE (simulation of common long-standing drinking of green tea). The aim of the study was to evaluate the benefits/risks of dietary supplements with GTE and/or regular drinking of green tea for obese individuals.

\section{MATERIALS AND METHODS}

\section{Chemicals}

Protease inhibitor cocktail tablets (EDTA free Complete Protease Inhibitor Cocktail Tablets) were supplied by Roche (Basel, Switzerland), SOD Assay Kit-WST by Dojindo (Tabaru, Japan), Polyphenon 60, bicinchoninic acid kit for protein determination and all other chemicals (high performance liquid chromatography (HPLC) or analytical grade) were obtained from Sigma-Aldrich (St. Louis, MO, USA) and were of the highest purity available.

\section{Experimental animals}

Male NMRI mice obtained from Meditox (Czech Republic) were housed in air-conditioned animal quarters, with a $12 \mathrm{~h}$ light/dark cycle (light from $6 \mathrm{AM}$ ). They were given ad libitum access to water and a standard chow diet (ST-1, Velaz, Czech Republic). The mice were cared for and used in accordance with the Guide for the Care and Use of Laboratory Animals (Protection of Animals from Misuse Act No. 246/92, Czech Republic). The Ethical Committee of Charles University in Prague, Faculty of Pharmacy in Hradec Králové, approved all animal experiment procedures (permit number: 34354/2010-30). Special pellets containing $0.1 \mathrm{~g}$ and $1 \mathrm{~g}$ of GTE (Polyphenon 60) in $1 \mathrm{~kg}$ of a standard chow diet and pellets without GTE were prepared by SEMED (Czech Republic).

For hypothalamic lesion-induced obesity, new born male mice were administered aqueous solution of monosodium glutamate (MSG) subcutaneously from postnatal day 2 to 8 (from day 2 to 6 mice received $10 \mathrm{mg} /$ day, 2 following days
$20 \mathrm{mg}$ /day). Lean mice were treated with saline of osmolality corresponding to the MSG solution. At 7 months of age, obese mice were significantly heavier than lean mice $(61 \pm 3 \mathrm{vs}$. $44 \pm 1 \mathrm{~g} /$ mouse). In addition, obese mice developed hyperleptinemia (28x higher amount of leptin than lean mice) and hyperinsulinemia ( $7 x$ higher amount of insulin than lean mice) [Matouskova et al., 2015]. The obese mice were divided into 4 groups (11-13 mice per group): first group was given standard diet without Polyphenon 60 (GTE) for 28 days, second group consisted of mice fed GTE-enriched diet $(1 \mathrm{~g} / \mathrm{kg})$ for 28 days (GTE-H28), third group received GTE-enriched diet $(0.1 \mathrm{~g} / \mathrm{kg}$ ) for 28 days (GTE-L28), fourth group included mice fed standard diet without GTE for 25 days and subsequently GTE-enriched diet $(1 \mathrm{~g} / \mathrm{kg}$ ) for 3 days (GTE-H3). The GTE-enriched diet was provided by special prepared pellets (SEMED, Prague, Czech Republic) containing $1 \mathrm{~g}$ or $0.1 \mathrm{~g}$ of GTE in $1 \mathrm{~kg}$ of standard chow diet. The group of lean mice received a standard diet without GTE for 28 days. Each group of mice (11-13 animals) was housed together in one cage. The diet and tap water were available ad libitum. At 7 months of age, parameters such as body weight and food intake were monitored regularly each day for subsequent 4 weeks. After 28 days, mice were fasted for $12 \mathrm{~h}$ and sacrificed by cervical dislocation. Blood samples were collected into $\mathrm{K}_{3}$ EDTA coated plastic tubes, plasma and erythrocytes were separated immediately by centrifugation $\left(1000 \times \mathrm{g}, 10 \mathrm{~min}, 10^{\circ} \mathrm{C}\right)$. Liver and small intestine were removed, washed with phosphate buffered saline (PBS) containing protease inhibitor cocktail tablets (final concentration $1.2 \mathrm{mg} / \mathrm{mL}$ ) and immediately frozen in liquid nitrogen. All biological samples were stored in a freezer at $-80^{\circ} \mathrm{C}$. The experimental protocol is summarized in Figure 1.

\section{Determination of plasmatic insulin and leptin levels}

Leptin and insulin concentrations in serum were quantified by ELISA assay kits (BioVendor, Brno, Czech Republic) according to manufacturer's instructions.

\section{Oxidative stress parameters}

The analysis of oxidative stress parameters was carried out in pooled blood samples (11-13 animals) due to insufficient volume for analysis of individual mice samples. After centrifugation and plasma removal, erythrocytes were washed three times with PBS. Plasma and red blood cells samples were stored at $-80^{\circ} \mathrm{C}$ prior to analyses.

Selected parameters for evaluation of oxidative stress were determined using the methods described in our previous study [Bartikova et al., 2015].

\section{Preparation of subcellular fractions}

Nitrogen-frozen liver and small intestine of mice were thawed at room temperature and then were homogenized

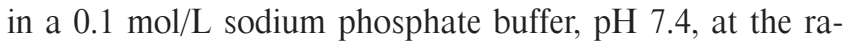
tio of 1:6 (w/v) (liver) or 1:5 (small intestine), using a Potter-Elvehjem homogenizer and sonication with Sonopuls (Bandelin, Germany). Protease inhibitor cocktail tablets were added to the buffer for intestine homogenization. The cytosolic fractions, prepared by fractional ultracentrifugation of the homogenate, were stored at $-80^{\circ} \mathrm{C}$. Bicinchoninic acid 


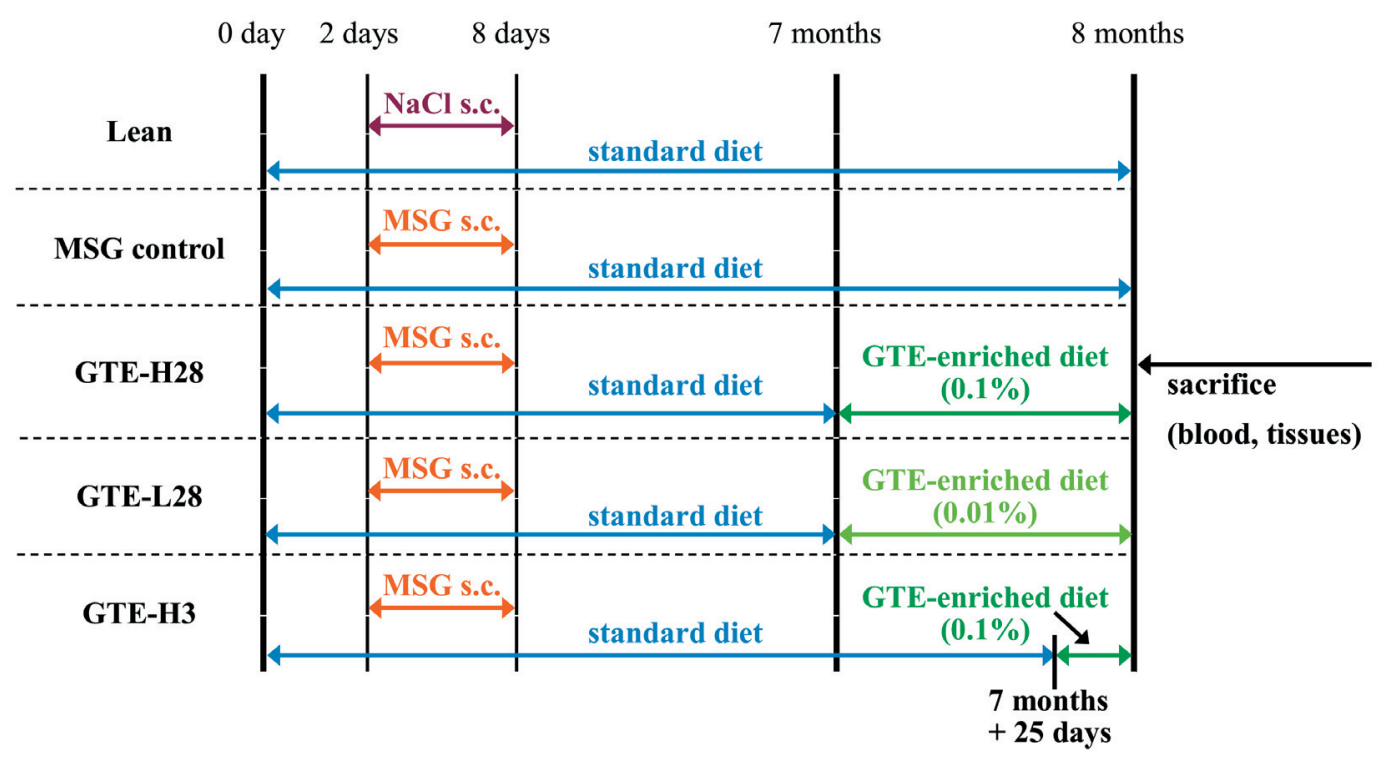

FIGURE 1. Outline of experimental groups. All newborn mice were administered monosodium glutamate (MSG) subcutaneously from postnatal day 2 to day 8 to induce obesity. Lean mice were treated with saline of osmolality corresponding to the MSG solution. Up to the age of 7 months, each experimental group consisting of 11-13 mice was fed standard diet. MSG and lean control group continued with standard diet for following 4 weeks. Group GTE-H28 was fed diet containing $1 \mathrm{~g}$ Polyphenon 60 (GTE)/kg during these 4 weeks, group GTE-L28 received GTE-enriched diet with 10 times lower amount of GTE $(0.1 \mathrm{~g} / \mathrm{kg})$ for the same period of time. The group GTE-H3 was administered standard diet at the age of 7 months for other 25 days and received GTE-enriched diet $(1 \mathrm{~g} / \mathrm{kg}$ ) only for 3 days before termination of the experiment. All mice were sacrificed at the age of 8 months.

method was used according to manufacturer's instructions (Sigma-Aldrich) for the measurement of protein concentrations.

\section{Enzyme assays}

Enzyme activities were assayed in the liver and intestinal cytosols. The amount of organic solvents in the final reaction mixtures did not exceed $10 \mathrm{~mL} / \mathrm{L}$. The amounts of rising product or diminishing substrate/cofactor were detected using microplate reader Tecan Infinite M200 (Tecan; Mannedorf, Switzerland).

Activity of GPx was assayed by a coupled reaction with GR as described in Flohé \& Günzler, [1984] and Handy et al. [2009]. CAT activity was measured according to the method described by Góth [1991]. The assay of SOD was performed using SOD Assay Kit-WST according to the general manufacturer's protocol. The activity of $\mathrm{NAD}(\mathrm{P}) \mathrm{H}$ :quinone oxidoreductase (NQO) was assayed spectrophotometrically by measuring cytochrome c reduction in the presence of NADH and menadione as an intermediate electron acceptor [Fitzsimmons et al., 1996; Cullen et al., 2003]. Total cytosolic GST activity was measured using 1-chloro-2,4-dinitrobenzene and GSH as substrates [Habig et al., 1974].

\section{Data analysis}

The assays of enzymatic activity were determined in a pooled cytosolic fraction in three independent experiments with 6 parallel samples in each. Oxidative stress parameters were determined in pooled blood samples and all assessments were performed in 3-4 replicates. All data were imported to GraphPad Prism (GraphPad Software, version 6.0) and the statistical significance of the results was analyzed with Student's $t$-test with Welch's correction. Differences were scored as statistically significant at the $P<0.05$.

\section{RESULTS}

Mice were fed a standard diet enriched with Polyphenon 60 (GTE), a purified form of a green tea extract with the following composition: $327 \mathrm{mg}$ of (-)-epigallocatechin, $125 \mathrm{mg}$ of (-)-epicatechin, $418 \mathrm{mg}$ of EGCG, $130 \mathrm{mg}$ of (-)-epicatechin gallate, and traces of (-)-gallocatechin and (-)-gallocatechin-3-gallate per $1 \mathrm{~g}$ of GTE [Matouskova et al., 2014]. It is necessary to state that all experiments with lean and MSG obese mice receiving the GTE-enriched diet were performed at the same time with the same mice litters, which enables direct comparison of the obtained results, part of which has been recently published [Matouskova et al., 2014; Bartikova et al., 2015; Tomankova et al., 2015].

\section{Effect of GTE-enriched diet on the body weight and food intake}

Despite lower food intake in GTE-L28 treated group in comparison to MSG control group and GTE-H28 group (Table 1$)$, weight of mice $(65 \pm 2 \mathrm{~g})$ did not significantly differ among individual groups.

\section{Effect of GTE-enriched diet on the antioxidant status parameters in plasma and erythrocytes}

Antioxidant status parameters were measured in plasma and erythrocytes pool samples from 4 groups: control MSG obese mice (MSG control) and obese mice treated with GTE in three different dosage schemes. The content of MDA and GSH and specific activities of GST, GPx, GR and CAT were used as markers of the antioxidant status in erythrocytes. Plasma served for the determination of MDA and total SHgroups concentrations.

In murine erythrocytes, a high dose of GTE consumed for 28 or 3 days (GTE-H28, GTE-H3) significantly decreased 
TABLE 1. Daily food intake and body weight of MSG mice without treatment (MSG control) and MSG mice treated with high $(\mathrm{H})$ or low (L) dose of Polyphenon 60 (GTE) for 28 days or high dose (H) for 3 days.

\begin{tabular}{l|c|c|c|c}
\hline & $\begin{array}{c}\text { MSG } \\
\text { control }\end{array}$ & GTE-H28 & GTE-L28 & GTE-H3 \\
\hline $\begin{array}{l}\text { Body weight } \\
\text { g/mouse }\end{array}$ & $65 \pm 2$ & $66 \pm 3$ & $63 \pm 4$ & $65 \pm 3$ \\
$\begin{array}{l}\text { Food intake } \\
\text { g/mouse/daily }\end{array}$ & $4.3 \pm 0.1$ & $4.3 \pm 0.1$ & $3.8 \pm 0.1 \boldsymbol{\nabla}$ & - \\
\hline
\end{tabular}

Mean values with symbol $(\boldsymbol{\nabla})$ indicate a significant decrease in comparison to MSG control using Student's t-test with Welch's correction $(\mathrm{P}<0.05)$.

TABLE 2. Specific activities of antioxidant enzymes and glutathione and malondialdehyde contents in erythrocytes of MSG mice without treatment (MSG control) and MSG mice treated with high $(\mathrm{H})$ or low (L) dose of Polyphenon 60 (GTE) for 28 days or high dose (H) for 3 days.

\begin{tabular}{|c|c|c|c|c|}
\hline & $\begin{array}{l}\text { MSG } \\
\text { control }\end{array}$ & GTE-H28 & GTE-L28 & GTE-H3 \\
\hline $\begin{array}{l}\text { Malondialdehyde } \\
(\mu \mathrm{mol} / \mathrm{g} \mathrm{Hb})\end{array}$ & $422 \pm 15$ & $433 \pm 14$ & $400 \pm 10$ & $420 \pm 10$ \\
\hline $\begin{array}{l}\text { Glutathione } \\
(\mu \mathrm{mol} / \mathrm{g} \mathrm{Hb})\end{array}$ & $111 \pm 4$ & $93 \pm 2 \boldsymbol{\nabla}$ & $99 \pm 9$ & $103 \pm 6$ \\
\hline $\begin{array}{l}\text { Glutathione } \\
\text { S-transferase } \\
\text { ( } \mu \text { kat/g Hb) }\end{array}$ & $0.50 \pm 0.13$ & $0.61 \pm 0.16$ & $0.54 \pm 0.08$ & $0.39 \pm 0.05$ \\
\hline $\begin{array}{l}\text { Glutathione } \\
\text { peroxidase } \\
(\mu \text { kat/g Hb) }\end{array}$ & $11.7 \pm 1.2$ & $9.9 \pm 0.2$ & $11.8 \pm 1.2$ & $10.7 \pm 0.9$ \\
\hline $\begin{array}{l}\text { Glutathione } \\
\text { reductase } \\
\text { ( } \mu \text { kat/g Hb) }\end{array}$ & $120 \pm 17$ & $60 \pm 8 \boldsymbol{\nabla}$ & $97 \pm 15$ & $59 \pm 12 \boldsymbol{\nabla}$ \\
\hline $\begin{array}{l}\text { Catalase } \\
\text { (mkat/g Hb) }\end{array}$ & $6.6 \pm 0.1$ & $6.2 \pm 0.1 \boldsymbol{\nabla}$ & $6.6 \pm 0.1$ & $5.8 \pm 0.1 \boldsymbol{\nabla}$ \\
\hline
\end{tabular}

All values are related to the level of hemoglobin $(\mathrm{Hb})$ and represent mean \pm S.D. $(n=3-4)$ from experiments with pooled samples of erythrocytes. Mean values with a symbol indicate a significant $(\mathrm{P}<0.05)$ decrease ( $\mathbf{\nabla})$ in comparison to MSG control using Student's t-test with Welch's correction.

TABLE 3. Concentration of malondialdehyde and SH groups related to amount of proteins in MSG mice without treatment (MSG control) and MSG mice treated with high $(\mathrm{H})$ or low $(\mathrm{L})$ dose of Polyphenon 60 (GTE) for 28 days or high dose (H) for 3 days.

\begin{tabular}{l|c|c|c|c}
\hline & $\begin{array}{c}\text { MSG } \\
\text { control }\end{array}$ & GTE-H28 & GTE-L28 & GTE-H3 \\
\hline $\begin{array}{l}\text { Malondialdehyde } \\
(\mu \text { mol/g proteins })\end{array}$ & $658 \pm 113$ & $858 \pm 29 \boldsymbol{\Delta}$ & $506 \pm 30$ & $765 \pm 85$ \\
$\begin{array}{l}\text { SH-groups } \\
(\mu \text { mol/g proteins })\end{array}$ & $86 \pm 4$ & $112 \pm 2 \boldsymbol{\Delta}$ & $96 \pm 6 \boldsymbol{\Delta}$ & $75 \pm 3 \boldsymbol{\nabla}$ \\
\hline
\end{tabular}

All values are related to total protein content $(\mathrm{g})$ and represent mean \pm S.D. $(n=4)$ from experiments with pooled samples of plasma. Mean values with a symbol indicate a significant increase $(\boldsymbol{\Delta})$ or decrease ( $\mathbf{\nabla})$ in comparison to MSG control using Student's t-test with Welch's correction $(\mathrm{P}<0.05)$

activity of GR and CAT. Long-term administration (GTE$\mathrm{H} 28)$ also diminished the concentration of GSH by $16.6 \%$. (Table 2). In plasma, there was observed elevation of $\mathrm{SH}$ groups after 4 weeks of GTE administration, both in high and low dose (GTE-H28, GTE-L28). Conversely, short-term overdose by catechins (GTE-H3) lowered the content of SHgroups by $12.7 \%$. In spite of positive influence of long-term high GTE dose on SH-groups, it caused elevation in MDA levels indicating increased lipid peroxidation (Table 3).

\section{Effect of GTE-enriched diet on the antioxidant enzymes in liver and small intestine}

Enzymatic activities of five antioxidant enzymes (CAT, SOD, NQO, GPx and GST) were assayed using specific substrates in cytosolic fraction of pooled samples. All parameters were determined in liver and small intestine and results obtained are summarized in Figures 2 and 3.

In comparison to MSG control group, no alterations were observed for GPx, CAT, SOD and GST after GTE administration in any dosage scheme both in liver and small intestine. The only enzyme affected by GTE-treatment was NQO, whose activity was surprisingly inhibited. In liver, a statistically significant impact on NQO activity (decrease by 19\%) was detected after short-term overdose (GTE-H3) (Figure 2). In small intestine, specific activities of NQO were decreased in GTE-L28 and GTE-H28 groups by $51.0 \%$ and $67.3 \%$ in comparison with MSG control, respectively.

\section{DISCUSSION}

The aim of our study was to bring out the complex information on the antioxidant status of obese mice after consumption of a green tea extract (GTE). Adult (7-month-old) mice with fully developed obesity accompanied with hyperleptinemia and hyperinsulinemia were fed a diet containing GTE. Oral administration of GTE in our study was chosen as it represents the most common way of catechins intake. However, oral administration of catechins is characterized by low systemic bioavailability due to their poor absorption but high intestinal exposure [Lambert et al., 2003, 2006]. Thus, except plasma, erythrocytes and liver, also small intestine was studied to obtain more complex information about the impact of the green tea extract in obese mice.

In obese mice, GTE in all dosage schemes did not affect average body weight, although food intake was reduced in group with 28-day low GTE dose. The level of insulin was significantly reduced after all GTE treatments; whereas leptin level was mildly decreased only in the group with short GTE treatment [Boušová et al. 2016]. Although the levels of insulin as well as leptin in obese mice after GTE treatment were still much higher than those in the lean mice [Boušová et al. 2016], a GTE-mediated decrease of these hormones level indicates a positive effect of GTE in obese animals.

The antioxidant status of organism reflects its ability to cope with oxidative stress caused mainly by ROS, which are generated through various sources (e.g. mitochondrial electron transport chain, radiation, pollution, and smoking). Deleterious reactions of ROS are controlled by antioxidant defense system comprising of exogenous antioxidants (e.g. tocopherols, carotenoids, vitamin $\mathrm{C}$ ), endogenous antioxidants (e.g. GSH, albumin, SH-groups), and antioxidant enzymes (e.g. SOD, CAT, GPx) [Wang et al., 2013]. Unlike these parameters showing the level of protection, malondialdehyde (MDA) represents one of the lipid peroxidation products 
GPx

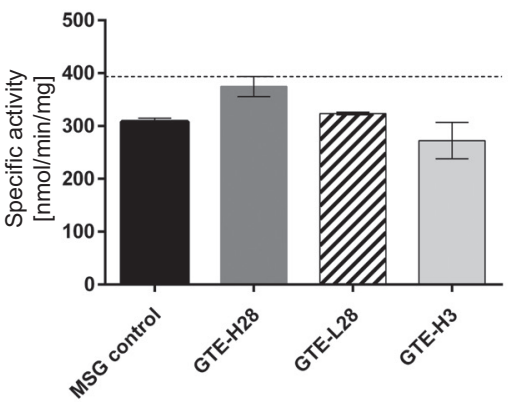

CAT

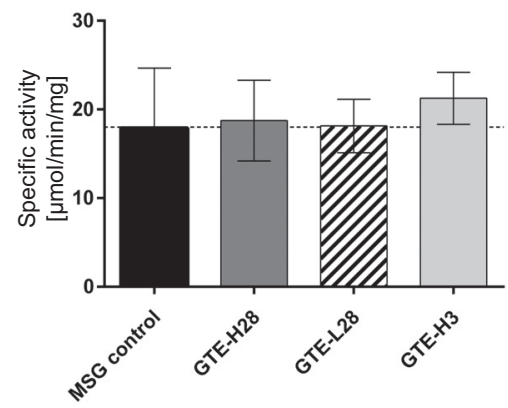

SOD

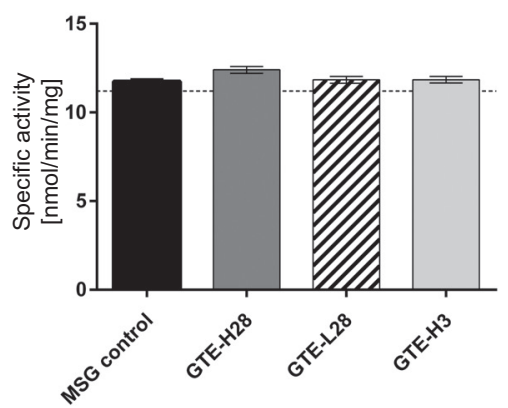

NQO

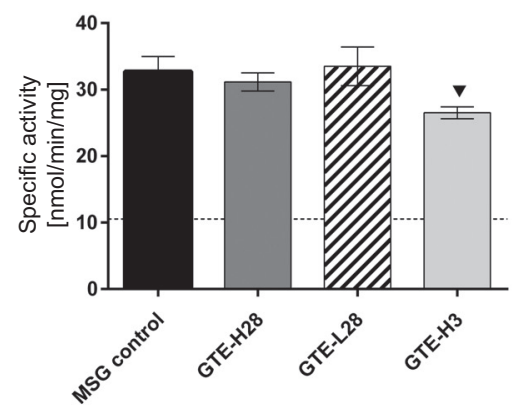

GST

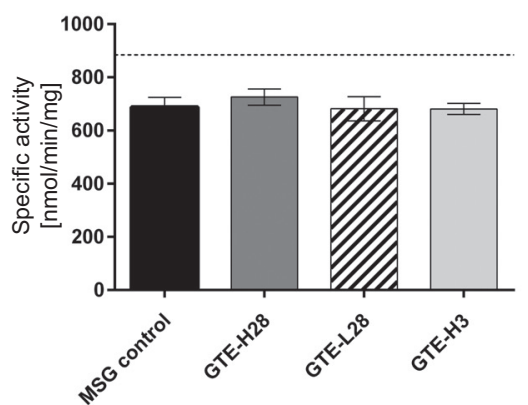

FIGURE 2. Specific activity of antioxidant enzymes in liver of MSG-obese control group and MSG-obese mice treated with high (H) or low (L) dose of Polyphenon 60 (GTE) for 28 days or high dose $(\mathrm{H})$ for 3 days.

VALUES REPRESENT MEAN \pm S.D. $(n=3)$ from experiments with pooled cytosol. Mean values with symbols indicate a significant decrease $(\boldsymbol{\nabla})$ in comparison to MSG control using Student's t-test with Welch's correction $(\mathrm{P}<0.05)$. Horizontal line indicates the value of enzyme activity obtained in the group of control lean mice.

GPx

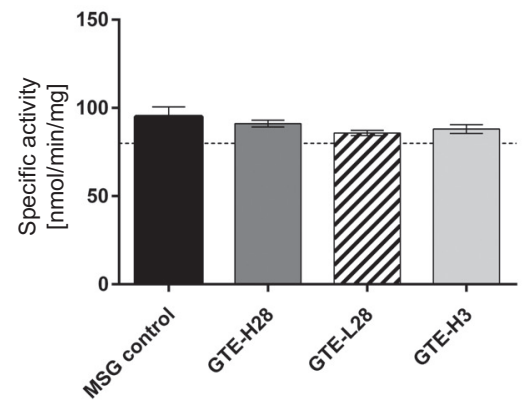

CAT

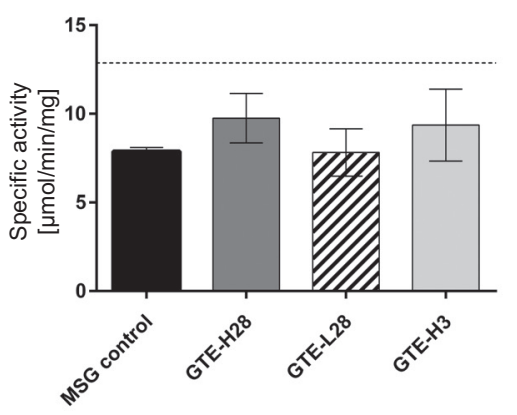

NQO

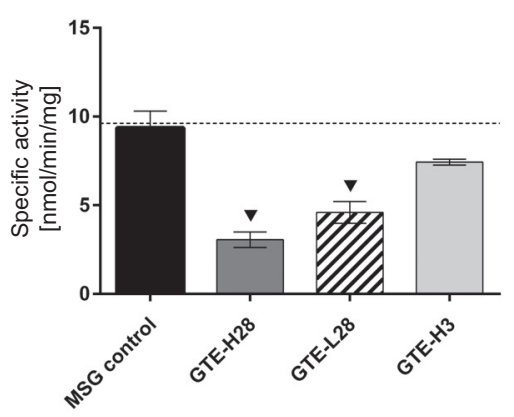

SOD

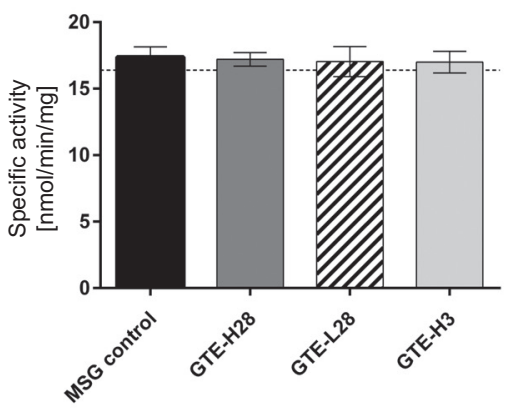

GST

FIGURE 3. Specific activity of antioxidant enzymes in small intestine of MSG-obese control group and MSG-obese mice treated with high (H) or low (L) dose of Polyphenon 60 (GTE) for 28 days or high dose (H) for 3 days.

Values represent mean \pm S.D. $(n=3)$ from experiments with pooled cytosol. Mean values with symbols indicate a significant decrease $(\boldsymbol{\nabla})$ in comparison to MSG control using Student's t-test with Welch's correction $(\mathrm{P}<0.05)$. Horizontal line indicates the value of enzyme activity expression obtained in the group of control lean mice. 
and is a marker of oxidative damage [Del Rio et al., 2005]. Although GST is involved mainly in biotransformation of xenobiotics, it works as an antioxidant enzyme as well, since it catalyzes the transformation of peroxides to less toxic products by conjugating them to GSH [Seeley et al., 2006].

In erythrocytes, several parameters of antioxidant status (MDA level, GR and CAT activity) were significantly higher in obese mice compared to their respective lean counterparts [Bartikova et al., 2015]. It can be caused by elevated ROS generation during the obesity [Picklo et al., 2012; Savini et al., 2013], which may subsequently induce antioxidant enzymes through the activation of $\mathrm{Nrf} 2$ antioxidant-responsive pathway [Na \& Surh, 2008]. As GTE did not enhance the activity of antioxidant enzymes, it might seem that it does not improve antioxidant defense. However, other mechanisms of lowering ROS, e.g. direct ROS scavenging, can take place and antioxidant enzymes thus cease to be subject to induction. Taken together, neither short-term nor long lasting GTE overdose showed clearly a positive effect. Moreover, GTE in high doses acted rather negatively as it altered undesirably some of the tested parameters (lower GSH level and higher content of MDA in GTE-H28 group).

The outcomes showing more positive features of tea catechins on the antioxidant status were obtained in the study with male Wistar rats fed an atherogenic diet and administered intraperitoneally isolated EGCG for 15 days. This treatment resulted in higher activities of SOD, CAT and GPx, increased GSH levels and reduced MDA content in erythrocytes [Ramesh et al., 2008]. This discrepancy might be caused by study design using different animals, form of catechins, dosage and way of their administration. In our previous study with non-obese mice, but otherwise with the same experimental design and performed at the same time as here reported experiments, we revealed no changes in the tested parameters, only elevation of SH-groups [Bartikova et al., 2015].

Administration of the green tea extract influenced the catalytic activity only of hepatic and intestinal NQO, other enzymatic activities remained unchanged. Same as in our study, the lowered NQO activity and unchanged activity of GPX, CAT, SOD in liver were revealed in rats fed semisynthetic diets enriched with catechin $(2 \mathrm{~g} / \mathrm{kg})$ for 3 weeks [Wiegand et al., 2009]. NQO catalyzes two-electron reduction of quinones, thereby preventing one-electron reduction of quinones that would cause redox cycling with generation of superoxide. The inhibition of NQO found in this study may lead to an enhanced level of ROS. In contrast, several previously published studies reported induction of antioxidant enzymes after consumption of green tea [Khan et al., 1992; Lin et al., 1998; Khan et al., 2007; Park et al., 2011]. However, all these studies were performed in non-obese individuals and with doses of green tea exceeding those used in our study. Based on our previous research, the obesity may be really the cause of the distinct sensitivity of tissue antioxidant enzymes to green tea catechins. Our in vivo study with non-obese mice, but the same experimental design as in the presented one, showed a different effect of GTE on the activity of NQO (increase), GPx and GST (decrease) [Bartikova et al., 2015]. Moreover, this dissimilarity can be connected with the fact that obesity itself altered the activity of these enzymes in comparison to the non-obese rodents [Noeman et al., 2011; Matouskova et al., 2015], which may be caused by elevated expression of Nrf2 in MSG-obese mice [Matouskova et al., 2015]. Moreover, the effect of green tea polyphenols on the antioxidant system of rodents is concentration-dependent with high doses $(5-10 \mathrm{~g} / \mathrm{kg}$ of the diet) causing down-regulation of Nrf2-dependent antioxidant enzymes in the liver and kidney [Murakami, 2014].

\section{CONCLUSIONS}

In conclusion, in vivo administration of GTE in obese mice did affect average body weight and did not induce antioxidant enzymes in liver and small intestine. Moreover, some of our results indicate that consumption of GTE, especially in high doses, could make antioxidant defense in obese animals even worse.

\section{ACKNOWLEDGEMENT}

This work was supported by the Czech Science Foundation (grant No P303/12/G163).

\section{CONFLICT OF INTEREST}

Authors declare no conflict of interest.

\section{REFERENCES}

1. Afrin S., Gasparrini M., Forbes-Hernandez T.Y., Reboredo-Rodriguez P., Mezzetti B., Varela-Lopez A., Giampieri F., Battino M., Promising health benefits of the strawberry: A focus on clinical studies. J. Agric. Food Chem., 2016, 64, 4435-4449.

2. Akaberi M., Hosseinzadeh H., Grapes (Vitis vinifera) as a potential candidate for the therapy of the metabolic syndrome. Phytotherap. Res., 2016, 30, 540-556.

3. Alarcon-Aguilar F.J., Zamilpa A., Perez-Garcia M.D., Almanza-Perez J.C., Romero-Nunez E., Campos-Sepulveda E.A., Vazquez-Carrillo L.I., Roman-Ramos R., Effect of Hibiscus sabdariffa on obesity in MSG mice. J. Ethnopharmacol., 2007, 114, 66-71.

4. Amiot M.J., Riva C., Vinet A., Effects of dietary polyphenols on metabolic syndrome features in humans: a systematic review. Obesity Rev., 2016, 17, 573-586.

5. Bartikova H., Skalova L., Valentova K., Matouskova P., Szotakova B., Martin J., Kvita V., Bousova I., Effect of oral administration of green tea extract in various dosage schemes on oxidative stress status of mice in vivo. Acta Pharm., 2015, 65, 65-73.

6. Boušová I., Matoušková P., Bártíková H., Szotáková B. Hanušová V., Tománková V., Anzenbacherová E., Lišková B., Anzenbacher P., Skálová L., Influence of diet supplementation with green tea extract on drug-metabolizing enzymes in a mouse model of monosodium glutamate-induced obesity. Eur. J. Nutr., 2016, 55, 361-371.

7. Chacko S.M., Thambi P.T., Kuttan R., Nishigaki I., Beneficial effects of green tea: a literature review. Chin Med, 2010, 5, 13.p

8. Cullen J.J., Hinkhouse M.M., Grady M., Gaut A.W., Liu J., Zhang Y.P., Weydert C.J., Domann F.E., Oberley L.W., Dicumarol inhibition of NADPH:quinone oxidoreductase induces 
growth inhibition of pancreatic cancer via a superoxide-mediated mechanism. Cancer. Res., 2003, 63, 5513-5520

9. Del Rio D., Stewart A.J., Pellegrini N., A review of recent studies on malondialdehyde as toxic molecule and biological marker of oxidative stress. Nutr. Metab. Cardiovasc. Dis., 2005, 15, 316-328.

10. Fitzsimmons S.A., Workman P., Grever M., Paull K., Camalier R., Lewis A.D., Reductase enzyme expression across the National Cancer Institute Tumor cell line panel: correlation with sensitivity to mitomycin C and EO9. J. Natl. Cancer Inst., 1996, 88, 259-269.

11. Flohé L., Günzler W.A., Assays of glutathione peroxidase. Methods Enzymol., 1984, 105, 114-121.

12. Fujimoto M., Tsuneyama K., Fujimoto T., Selmi C., Gershwin M.E., Shimada Y., Spirulina improves non-alcoholic steatohepatitis, visceral fat macrophage aggregation, and serum leptin in a mouse model of metabolic syndrome. Dig. Liver Dis., 2012a, 44, 767-774.

13. Fujimoto M., Tsuneyama K., Chen S.Y., Nishida T., Chen J.L., Chen Y.C., Fujimoto T., Imura J., Shimada Y., Study of the effects of monacolin $\mathrm{k}$ and other constituents of red yeast rice on obesity, insulin-resistance, hyperlipidemia, and nonalcoholic steatohepatitis using a mouse model of metabolic syndrome. Evid. Based Complement. Alternat. Med., 2012b, 892697.

14. Góth L., A simple method for determination of serum catalase activity and revision of reference range. Clin. Chim. Acta, 1991, 196, 143-151.

15. Habig W.H., Pabst M.J., Jakoby W.B., Glutathione S-Transferases: The first enzymatic step in mercapturic acid formation. J. Biol. Chem., 1974, 249, 7130-7139.

16. Handy D.E., Lubos E., Yang Y., Galbraith J.D., Kelly N., Zhang Y.Y., Leopold J.A., Loscalzo J., Glutathione peroxidase-1 regulates mitochondrial function to modulate redox-dependent cellular responses. J. Biol. Chem., 2009, 284, 11913-11921.

17. Johnson R., Bryant S., Huntley A.L., Green tea and green tea catechin extracts: an overview of the clinical evidence. Maturitas, 2012, 73, 280-287.

18. Khan N., Afaq F., Saleem M., Ahmad N., Mukhtar H., Targeting multiple signaling pathways by green tea polyphenol (-)-epigallocatechin-3-gallate. Cancer Res., 2006, 66, 2500-2505.

19. Khan S.A., Priyamvada S., Arivarasu N.A., Khan S., Yusufi A.N., Influence of green tea on enzymes of carbohydrate metabolism, antioxidant defense, and plasma membrane in rat tissues. Nutrition, 2007, 23, 687-695.

20. Khan S.G., Katiyar S.K., Agarwal R., Mukhtar H., Enhancement of antioxidant and phase II enzymes by oral feeding of green tea polyphenols in drinking water to SKH-1 hairless mice: possible role in cancer chemoprevention. Cancer Res., 1992, 52, 4050-4052 .

21. Lambert J.D., Lee M.J., Diamond L., Ju J., Hong J., Bose M., Newmark H.L., Yang C.S., Dose-dependent levels of epigallocatechin-3-gallate in human colon cancer cells and mouse plasma and tissues. Drug Metab. Dispos., 2006, 34, 8-11.

22. Lambert J.D., Lee M.J., Lu H., Meng X., Hong J.J., Seril D.N., Sturgill M.G., Yang C.S., Epigallocatechin-3-gallate is absorbed but extensively glucuronidated following oral administration to mice. J. Nutr., 2003, 133, 4172-4177.

23. Lin Y.L., Cheng C.Y., Lin Y.P., Lau Y.W., Juan I.M., Lin J.K., Hypolipidemic effect of green tea leaves through induction of an- tioxidant and phase II enzymes including superoxide dismutase, catalase, and glutathione S-transferase in rats. J. Agric. Food Chem., 1998, 46, 1893-1899.

24. Martin M.A., Serrano A.B., Ramos S., Pulido M.I., Bravo L., Goya L., Cocoa flavonoids up-regulate antioxidant enzyme activity via the ERK1/2 pathway to protect against oxidative stress-induced apoptosis in HepG2 cells. J. Nutr. Biochem., 2010, 21, 196-205.

25. Matouskova P., Bartikova H., Bousova I., Levorova L., Szotakova B., Skalova L., Drug-metabolizing and antioxidant enzymes in monosodium L-glutamate obese mice. Drug Metab. Dispos., 2015, 43, 258-265.

26. Matouskova P., Bartikova H., Bousova I., Szotakova B., Martin J., Skorkovska J., Hanusova V., Tomankova V., Anzenbacherova E., Liskova B., Anzenbacher P., Skalova L., Effect of defined green tea extract in various dosage schemes on drug-metabolizing enzymes in mice in vivo. J. Funct. Foods, 2014, 10, 327-335.

27. Matyskova R., Maletinska L., Maixnerova J., Pirnik Z., Kiss A., Zelezna B., Comparison of the obesity phenotypes related to monosodium glutamate effect on arcuate nucleus and/or the high fat diet feeding in C57BL/6 and NMRI mice. Physiol. Res., 2008, 57, 727-734.

28. Murakami A., Dose-dependent functionality and toxicity of green tea polyphenols in experimental rodents. Arch. Biochem. Biophys., 2014, 557, 3-10.

29. Na H.K., Surh Y.J., Modulation of Nrf2-mediated antioxidant and detoxifying enzyme induction by the green tea polyphenol EGCG. Food Chem. Toxicol., 2008, 46, 1271-1278.

30. Noeman S.A., Hamooda H.E., Baalash A.A., Biochemical study of oxidative stress markers in the liver, kidney and heart of high fat diet induced obesity in rats. Diabetol. Metab. Syndr., 2011, $3,17-22$.

31. Olney J.W., Brain lesions, obesity, and other disturbances in mice treated with monosodium glutamate. Science, 1969, 164, 719$-721$.

32. Osei-Hyiaman D., Liu J., Zhou L., Godlewski G., Harvey-White J., Jeong W.I., Batkai S., Marsicano G., Lutz B., Buettner C., Kunos G., Hepatic CB(1) receptor is required for development of diet-induced steatosis, dyslipidemia, and insulin and leptin resistance in mice. J. Clin. Invest., 2008, 118, 3160-3169.

33. Park H.J., DiNatale D.A., Chung M.Y., Park Y.K., Lee J.Y., Koo S.I., O'Connor M., Manautou J.E., Bruno R.S., Green tea extract attenuates hepatic steatosis by decreasing adipose lipogenesis and enhancing hepatic antioxidant defenses in ob/ob mice. J. Nutr. Biochem., 2011, 22, 393-400.

34. Picklo M., Claycombe K.J., Meydani M., Adipose Dysfunction, Interaction of Reactive Oxygen Species, and Inflammation. Adv. Nutr., 2012, 3, 734-735.

35. Ramesh E., Elanchezhian R., Sakthivel M., Jayakumar T., Senthil Kumar R.S., Geraldine P., Thomas P.A., Epigallocatechin gallate improves serum lipid profile and erythrocyte and cardiac tissue antioxidant parameters in Wistar rats fed an atherogenic diet. Fundam. Clin. Pharmacol., 2008, 22, 275-284.

36. Savini I., Catani M.V., Evangelista D., Gasperi V., Avigliano L., Obesity-associated oxidative stress: strategies finalized to improve redox state. Int. J. Mol. Sci., 2013, 14, 10497-10538.

37. Seeley S.K., Poposki J.A., Maksimchuk J., Tebbe J., Gaudreau J., Mannervik B., Bull A.W., Metabolism of oxidized linoleic acid by glutathione transferases: peroxidase activity toward 13-hy- 
droperoxyoctadecadienoic acid. Biochim. Biophys. Acta, 2006, 1760, 1064-1070.

38. Tomankova V., Liskova B., Skalova L., Bartikova H., Bousova I., Jourova L., Anzenbacher P., Ulrichova J., Anzenbacherova E., Altered cytochrome P450 activities and expression levels in the liver and intestines of the monosodium glutamate-induced mouse model of human obesity. Life Sci., 2015, 133, 15-20.

39. Wang Y., Chun O.K., Song W.O., Plasma and dietary antioxidant status as cardiovascular disease risk factors: A Review of human studies. Nutrients, 2013, 5, 2969-3004.
40. Wiegand H., Boesch-Saadatmandi C., Regos I., Treutter D., Wolffram S., Rimbach G., Effects of quercetin and catechin on hepatic glutathione-S transferase (GST), NAD(P)H quinone oxidoreductase 1 (NQO1), and antioxidant enzyme activity levels in rats. Nutr. Cancer, 2009, 61, 717-722.

Submitted: 11 April 2016. Revised: 7 October and 10 November 2016. Accepted: 14 November 2016. Published on-line: 17 March 2017. 